Article

\title{
Influence of Single- and Multi-Wall Carbon Nanotubes on Magnetohydrodynamic Stagnation Point Nanofluid Flow over Variable Thicker Surface with Concave and Convex Effects
}

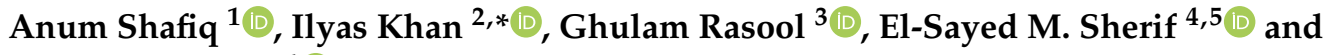 \\ Asiful H. Sheikh ${ }^{4}$ (D) \\ 1 School of Mathematics and Statistics, Nanjing University of Information Science and Technology, \\ Nanjing 210044, China; anumshafiq@ymail.com \\ 2 Faculty of Mathematics and Statistics, Ton Duc Thang University, Ho Chi Minh City 72915, Vietnam \\ 3 School of Mathematical Sciences, Yuquan Campus, Zhejiang University, Hangzhou 310027, China; \\ grasool@zju.edu.cn \\ 4 Center of Excellence for Research in Engineering Materials (CEREM), King Saud University, P.O. Box, 800, \\ Al-Riyadh 11421, Saudi Arabia; esherif@ksu.edu.sa (E.-S.M.S.); aseikh@ksu.edu.sa (A.H.S.) \\ 5 Electrochemistry and Corrosion Laboratory, Department of Physical Chemistry, National Research Centre, \\ El-Behoth St. 33, Dokki, Cairo 12622, Egypt \\ * Correspondence: ilyaskhan@tdtu.edu.vn
}

Received: 8 December 2019; Accepted: 2 January 2020; Published: 8 January 2020

\begin{abstract}
This paper reports a theoretical study on the magnetohydrodynamic flow and heat exchange of carbon nanotubes (CNTs)-based nanoliquid over a variable thicker surface. Two types of carbon nanotubes (CNTs) are accounted for saturation in base fluid. Particularly, the single-walled and multi-walled carbon nanotubes, best known as SWCNTs and MWCNTs, are used. Kerosene oil is taken as the base fluid for the suspension of nanoparticles. The model involves the impact of the thermal radiation and induced magnetic field. However, a tiny Reynolds number is assumed to ignore the magnetic induction. The system of nonlinear equations is obtained by reasonably adjusted transformations. The analytic solution is obtained by utilizing a notable procedure called optimal homotopy analysis technique (O-HAM). The impact of prominent parameters, such as the magnetic field parameter, Brownian diffusion, Thermophoresis, and others, on the dimensionless velocity field and thermal distribution is reported graphically. A comprehensive discussion is given after each graph that summarizes the influence of the respective parameters on the flow profiles. The behavior of the friction coefficient and the rate of heat transfer (Nusselt number) at the surface $(y=0)$ are given at the end of the text in tabular form. Some existing solutions of the specific cases have been checked as the special case of the solution acquired here. The results indicate that MWCNTs cause enhancement in the velocity field compared with SWCNTs when there is an increment in nanoparticle volume fraction. Furthermore, the temperature profile rises with an increment in radiation estimator for both SWCNT and MWCNT and, finally, the heat transfer rate lessens for increments in the magnetic parameter for both types of nanotubes.
\end{abstract}

Keywords: kerosene oil-based fluid; stagnation point; carbon nanotubes; variable thicker surface; thermal radiation

\section{Introduction}

The idea of nanofluid was first introduced by Choi [1] in 1995. In his pioneering study, Choi named nanofluids as one of the most essential type of fluids for an enhanced heat transfer rate. 
Nanofluids are formed by suspending nanoparticles of interested metals in the base fluid. To date, different types of nanoparticles as well as the base fluids are used in the literature. Some of them are magnetic nanoparticles, polymeric nanoparticles, carbon nanotubes, liposomes, quantum dots, metallic nanoparticles, dendrimers, polymeric nanoparticles, and many others. The base fluids are always water, oil, and/or ethylene glycol. The metallic nanoparticles are alumina, carbides, copper, metal oxides, and nitrides, whereas non-metallic nanoparticles are graphite and the well-known carbon nanotubes. Researchers have used different combinations of nanoparticles and base fluids, however, nobody gave a final decision about which combination of nanoparticles and base fluid can give a better enhancement in the heat transfer rate (see, for example, the works of [2-18]).

In addition to the above discussion, each type of nanoparticle and base fluid has its unique importance. In this work, carbon nanotubes (CNTs) were used as nanoparticles suspended in Kerosene oil, chosen as base fluid. CNTs are elongated, tubular structure, and 1-2 nm in diameter (see, for example, the works of [19-23]). However, the best CNTs are those arranged in the form of hexagonal network of carbon atoms rolled up to form a steam-less hollow cylinder (Choi and Zhang [24]). CNTs were first discovered by a Japanese physicist Sumio Iijma in 1991 for multiple wall nanotubes (Sumio [25]). However, it took less than two years before single wall nanotubes were discovered. Several researchers these days are taking keen interest in studying CNTs owing to their unique nanostructures, high thermal conductivity, and exceptional mechanical strength and corrosion resistance. These novel characteristics of CNTs make them useful in industry such as solar cell, nanotube transistors, lithium ion batteries, chemical sensors, and so on. The theoretical and experimental researchers usually use two types of CNTs, namely single-walled carbon nanotubes (SWNTs) and multi-walled carbon nanotubes (MWNTs). Choi [26] found anomalous thermal conductivity enhancement in nanotubes' suspensions. Hone [27] studied, in details, the thermal properties of CNTs. Kamali and Binesh [28] numerically investigated heat transfer enhancement in non-Newtonian nanofluids using CNTs. Prajapati et al. [29], Kumaresan and Velraj [30], and Wang et al. [31] also provided some interesting studies on CNTs. Khan et al. [32] examined heat transfer using CNTs and fluid flow with Navier slip boundary conditions. Noreen et al. [33] used CNTs and analyzed thermal and velocity slips on Magnetohydrodynamics (MHD) peristaltic flow in an asymmetric channel. Noreen and Khan [34] studied heat transfer using individual MWCNTs owing to the metachronal beating of cilia. Ebaid and Sharif [35] suspended CNTs in a base fluid and studied the effect of a magnetic field on fluid motion and enhanced the rate of heat transfer of nanofluids using CNTs (also see the works of [36-39]). Zhang et al. [40] examined the effects of surface modification on the thermal conductivity and stability of the suspension formulated using the CNTs. Aman et al. [41] suspended CNTs in four different types of molecular liquid and studied heat transfer enhancement in the free convection flow of Maxwell nanofluids. Zhang experimentally investigated the heat transfer of CNTs membranes. Soleimani et al. [42] studiedthe impact of carbon nanotubes-based nanofluid on oil recovery efficiency using core flooding. Details about the MWCNTs were provided by Taheriang et al. [43] for enhanced thermophysical properties of nanofluids in a critical review. Wang et al. [44], in their review paper, studied mechanisms and applications of CNTs in terahertz devices. Pop et a. [45] studied the well-known stagnation point fluid flow over a stretching sheet involving the heat transfer factor due to radiation. Sharma and Singh [46] investigated stagnation point flow past a linearly stretching sheet with additional effects of variable thermal conductivity, heat source/sink, and MHD. Some other important studies with some interesting experimental findings are given in the works of [47-60] and cross references cited therein.

The basic objective of this examination is to report an MHD flow of nanofluid with Kerosene oil as base fluid and CNTs as nanoparticles over a variable thicker surface. Such formulation is not found in the literature so far. Two types of CNTs (SWCNTs and MWCNTs) are chosen. The problem is first arranged in suitable nonlinear differential equations using reasonable transformations. Analytic solution is obtained by utilizing a notable procedure called the optimal homotopy analysis technique (O-HAM). Several plots are generated to discuss the physical behavior of embedded parameters on the dimensionless velocity field and thermal distribution. The results for skin-friction (wall-drag) 
coefficient and rate of heat transfer (Nusselt factor) are computed in tabular data form. The present results are successfully reduced to the published results in the literature when compared.

\section{Mathematical Formulation}

The present communication reports a theoretical study on the magnetohydrodynamic flow and heat exchange of carbon nanotubes (CNTs)-based nanoliquid over a variable thicker surface. Kerosene oil is taken as the base fluid for the suspension of nanoparticles. Two types of carbon nanotubes (CNTs) are accounted for saturation in base fluid. Flow phenomenon is investigated in the presence of applied magnetic field. SWCNTs and MWCNTs are utilized as nanomaterials and kerosine oil is as base liquid. The impact of radiation and viscous dissipation are considered in the heat analysis. The thickness of the surface mentioned by $y=B(x+b)^{\frac{1-m}{2}}$ is variable. The ambient temperature is taken to be constant. The physical model can be seen in Figure 1.

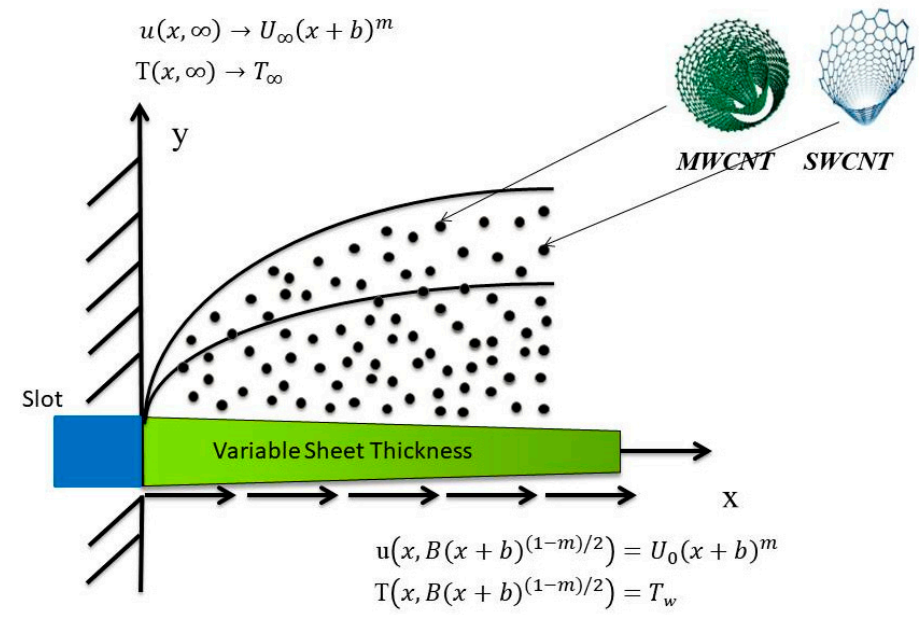

Figure 1. Physical flow model. MWCNT, multi-walled carbon nanotube; SWCNT, single-walled carbon nanotube.

The boundary layer equations for the aforementioned problem (see, for example, the works of [49-52]) are as follows:

$$
\begin{gathered}
\frac{\partial u}{\partial x}+\frac{\partial v}{\partial y}=0 \\
u \frac{\partial u}{\partial x}+v \frac{\partial u}{\partial y}=U_{e} \frac{d U_{e}}{d x}+v_{n f} \frac{\partial^{2} u}{\partial^{2} y}-\frac{\sigma B_{0}^{2}}{\rho_{n f}}\left(U-U_{e}\right) \\
u \frac{\partial T}{\partial x}+v \frac{\partial T}{\partial y}=\alpha_{n f} \frac{\partial^{2} T}{\partial^{2} y}-\frac{1}{\rho C_{p}} \frac{\partial q_{r}}{\partial y}+\frac{v_{n f}}{\rho C_{p}}\left(\frac{\partial u}{\partial y}\right)^{2}
\end{gathered}
$$

where velocity components are $(u, v)$ along the $x$ - and $y$-axes, respectively; $T$ denotes the temperature; $\left(v_{n f}, \alpha_{n f}\right)$ denotes the effective kinematic viscosity and thermal diffusivity of nanoliquid, respectively; $\left(U_{w}, U_{e}\right)$ are defined as the stretching surface and free stream velocity, respectively; $q_{r}$ defines the radiative heat flux; and $C_{p}$ defines the specific heat. The fruitful characteristics of nanoliquids may be defined using the properties of base liquid and carbon nanotubes and the solid volume fraction of CNTs in the base liquids (see, for example, the works of [49-52]) as follows:

$$
\begin{aligned}
& \mu_{n f}=\frac{\mu_{f}}{(1-\varphi)^{2.5}}, v_{n f}=\frac{\mu_{n f}}{\rho_{n f}}, \rho_{n f}=(1-\varphi) \rho_{f}+\varphi \rho_{s}\left(C_{p}\right)_{\mathrm{CNT}^{\prime}} \\
& \alpha_{n f}=\frac{k_{n f}}{\rho_{n f}\left(C_{p}\right)_{n f}}, \frac{k_{n f}}{k_{f}}=\frac{(1-\varphi)+2 \varphi \frac{{ }^{{ }_{\mathrm{CNT}}}}{{ }^{\mathrm{CNT}}-k_{f}} \ln \frac{{ }^{k} \mathrm{CNT}{ }^{+k_{f}}}{2 k_{f}}}{(1-\varphi)+2 \varphi \frac{k f}{{ }_{{ }_{\mathrm{CNT}}-k_{f}}} \ln \frac{{ }^{{ }_{\mathrm{CNT}}+k_{f}}}{2 k_{f}}},
\end{aligned}
$$


where viscosity of nanoliquid is defined by $\mu_{n f}$; nanoparticle volume fraction is defined by $\varphi$; and density of liquid and CNTs are defined by $\rho_{f}$ and $\rho_{\mathrm{CNT}}$, respectively. Base liquid's thermal conductivity is defined by $k_{f}$; thermal conductivity of nanoliquids is defined by $k_{n f}$; the specific heat of nanoliquids, base liquid, and carbon nanotubes are defined by $\left(C_{p}\right)_{n f^{\prime}}\left(C_{p}\right)_{f^{\prime}}$ and $\left(C_{p}\right)_{\mathrm{CNTs}}$, respectively; while thermal conductivity of CNTs is defined by $k_{\mathrm{CNT}}$, with boundary conditions as follows:

$$
\begin{aligned}
& \text { at } y=B(x+b)^{\frac{1-m}{2}}, U_{w}(x)=U=U_{0}(x+b)^{m}, T=T_{w}, v=0, \\
& \text { as } y \rightarrow \infty, u \rightarrow U_{\infty}(x+b)^{m}=U_{e(x)}, \quad T \rightarrow T_{\infty} .
\end{aligned}
$$

Using Rosseland approximation, we get the accompanying articulation

$$
q_{r}=\frac{-4}{3} \frac{\sigma^{*}}{K^{*}} \frac{\partial T^{4}}{\partial y}=-\frac{16 \sigma^{*}}{3 K^{*}} T^{3} \frac{\partial T}{\partial y}
$$

where the mean absorption coefficient is defined by $k^{*}$, the Stefan-Boltzmann constant is defined by $\sigma^{*}$, and $T^{4}$ defined using Taylor series expansion about $T_{\infty}$ is

$$
T^{4}=4 T_{\infty}^{3} T-3 T_{\infty}^{4} .
$$

The state of surface firmly relies on $m$. It should be noted that, for $m=1$, the surface is flat; the thickness of the wall rises for $m<1$ and the surface shape becomes of the outer convex type. The wall thickness decreases for $m>1$ and, consequently, the surface shape becomes of the inner concave type; $m$ is accountable for the motion type, that is, for $m=0$, the motion is linear with constant velocity. Motion deceleration and accelerated are defined by $m<1$ and $m>1$. Employing the transformations

$$
\begin{aligned}
& \xi=y \sqrt{\frac{U_{o}(x+b)^{m-1}}{2 v_{f}}(m+1)}, \quad \psi=\sqrt{\frac{1}{m+1} 2 v_{f} U_{o}(x+b)^{m+1}} F(\xi), \Theta(\xi)=\frac{T-T_{\infty}}{T_{w}-T_{\infty}}, \\
& u=U_{o}(x+b)^{m} F^{\prime}(\xi), \quad v=-\sqrt{\frac{m+1}{2} v_{f} U_{o}(x+b)^{m-1}}\left[F+\xi F^{\prime} \frac{m-1}{m+1}\right]
\end{aligned}
$$

the incompressibility condition is consequently fulfilled and Equations (2), (3), and (5) are lessened to the following:

$$
\begin{gathered}
\left(\frac{1}{(1-\varphi)^{2.5}\left(1-\varphi+\varphi \frac{\rho_{\mathrm{CNT}}}{\rho_{f}}\right)}\right) F^{\prime \prime \prime}+F F^{\prime \prime}-\frac{2 m}{m+1}\left(F^{\prime}\right)^{2}+\frac{2 m}{m+1} A^{2}-M^{2}\left(F^{\prime}-A\right)=0, \\
\left(\frac{k_{n f} / k_{f}}{\left(1-\varphi+\varphi \frac{\left(\rho c_{p}\right)_{\mathrm{CNT}}}{\left(\rho c_{p}\right)_{f}}\right)}\right)\left(1+\frac{4}{3 k_{n f} / k_{f}} R_{d}\right) \Theta^{\prime \prime}+\operatorname{Pr} F \Theta^{\prime}+\operatorname{Pr} E c\left(F^{\prime \prime}\right)^{2}=0, \\
F^{\prime}(\alpha)=1, F(\alpha)=\alpha \frac{1-m}{1+m}, \Theta(\alpha)=0, \text { at } \alpha=B \sqrt{\frac{m+1}{2} \frac{U_{0}}{v_{f}}} \\
F^{\prime}(\infty) \rightarrow A, \Theta(\infty) \rightarrow 1 \quad \alpha \rightarrow \infty,
\end{gathered}
$$

where $\alpha=B \sqrt{\frac{m+1}{2} \frac{U_{0}}{v_{f}}}$ is the wall thickness parameter. Putting

$$
F(\xi)=f(\eta)=f(\xi-\alpha)
$$


The final equations in one variable form are given here:

$$
\begin{aligned}
& \left(\frac{1}{(1-\varphi)^{2.5}\left(1-\varphi+\varphi \frac{\rho_{\mathrm{CNT}}}{\rho_{f}}\right)}\right) f^{\prime \prime \prime}+f f^{\prime \prime}-\frac{2 m}{m+1}\left(f^{\prime}\right)^{2}+\frac{2 m}{m+1} A^{2}-M^{2}\left(f^{\prime}(\eta)-A\right)=0, \\
& \left(\frac{k_{n f} / k_{f}}{\left(1-\varphi+\varphi \frac{\left(\rho c_{p}\right)_{\mathrm{CNT}}}{\left(\rho c_{p}\right)_{f}}\right)}\right)\left(1+\frac{4}{3 k_{n f} / k_{f}} R_{d}\right) \theta^{\prime \prime}+\operatorname{Pr} f \theta^{\prime}+\operatorname{Pr} E c\left(f^{\prime \prime}\right)^{2}=0, \\
& f^{\prime}(0)=1, f(0)=\alpha \frac{1-m}{1+m}, \theta(0)=0, \text { at } \eta=0, \\
& f^{\prime}(\infty) \rightarrow A, \theta(\infty) \rightarrow 1 \quad \eta \rightarrow \infty,
\end{aligned}
$$

where $A$ is defined as ratio parameter, $M$ is defined as magnetic parameter, $R_{d}$ is defined as radiation estimator, Pr is defined as Prandtl number, and $E c$ is defined as the well-known Eckert number. Mathematically,

$$
A=\frac{U_{\infty}}{U_{0}}, M=\sqrt{\frac{\sigma B_{0}^{2}}{\rho c_{p}}}, R_{d}=\frac{4 \sigma^{*} T^{3}}{k_{f} K^{*}}, \operatorname{Pr}=\frac{\mu c_{p}}{k}, E c=\frac{U_{w}^{2}}{c_{p}\left(T_{w}-T_{\infty}\right)} .
$$

The expression of friction coefficient (wall-drag) and local Nusselt (the heat transfer) number are

$$
\begin{aligned}
& C_{f}=\frac{\tau_{w}}{\rho f U_{w}^{2}}, N u_{x}=\frac{(x+b) q_{w}}{k_{f}\left(T_{\infty}-T_{w}\right)}, \\
& \tau_{w}=u_{n f}\left(\frac{\partial u}{\partial y}\right)_{y=B(x+b)^{\frac{1-m}{2}}}, \quad q_{w}=-\kappa_{n f}\left(\frac{\partial T}{\partial y}\right)_{y=B(x+b)^{\frac{1-m}{2}} .}
\end{aligned}
$$

The dimensionless forms of the above parameters are

$$
C_{f} \operatorname{Re}_{x}^{\frac{1}{2}}=\frac{1}{(1-\varphi)^{2.5}} \sqrt{\frac{1}{2}(m+1)} f^{\prime \prime \prime}(0), N u_{x} \operatorname{Re}^{\frac{-1}{2}}=-\frac{k_{n f}}{k_{f}} \sqrt{\frac{1}{2}(m+1)} \theta^{\prime}(0),
$$

where $\operatorname{Re}_{x}=\frac{U_{w}(x+b)}{v_{f}}$ denotes Reynolds number.

\section{Mathematical Analysis}

\subsection{OHAM (BVPh 2.0)}

The governing problems are explained using BVPh 2.0, via the homotopy analysis method (HAM)-based Mathematica package. The BVPh 2.0 is simple to utilize. It simply needs to compose the required governing problems. For each governing equation, we select the proper auxiliary linear operators and accurate initial guess for every undetermined function. Expression of linear operators and initial guesses are

$$
\begin{gathered}
f_{0}(\eta)=A \eta+(1-A)(1-\exp (-\eta))-\alpha \frac{m-1}{m+1}, \\
\theta_{0}(\eta)=1-\exp (-\eta), \\
L_{f}(f)=\frac{d^{3} f}{d \eta^{3}}-\frac{d f}{d \eta}, L_{\theta}(\theta)=\frac{d^{2} \theta}{d \eta^{2}}-\theta,
\end{gathered}
$$

with

$$
\begin{gathered}
L_{f}\left[E_{1}+E_{2} \exp (\eta)+E_{3} \exp (-\eta)\right]=0, \\
L_{\theta}\left[E_{4} \exp (\eta)+E_{5} \exp (-\eta)\right]=0,
\end{gathered}
$$


above $E_{i}(i=1,2, \ldots, 5)$ shows arbitrary constants.

\subsection{Optimal Convergence Analysis}

The estimations of convergence control parameters $\left(h_{f}, h_{\theta}\right)$ in kerosene oil nanoliquids for both type of nanotubes, that is, SWCNTs and MWCNTs, are calculated through the boundary value problem solver package BVPh 2.0. We now continue to attain the solution of governing equations via Boundary value problem solver package BVPh 2.0. These governing equations hold two unknown convergence estimates $\left(h_{f}, h_{\theta}\right)$. Optimal estimates of these parameters are calculated by the total minimum error. It ought to be seen that the convergence estimates assume an essential part in the frame of the homotopy analysis method (HAM), and HAM differs from other analytical techniques. To enormously diminish the Central Processing Unit (CPU) time, the average residual error at the $k$ th-order of estimate is characterized by

$$
\varepsilon_{\theta}^{f}\left(h_{f}, h_{\theta}\right)=\frac{1}{N+1} \sum_{J=0}^{N}\left[\sum_{i=0}^{N}\left(f_{i}\right)_{\eta=j \pi}\right]^{2},
$$

and

$$
\varepsilon_{\theta}^{f}\left(h_{f}, h_{\theta}\right)=\frac{1}{N+1} \sum_{J=0}^{N}\left[\sum_{i=0}^{k}\left(f_{i}\right)_{\eta=j \pi^{\prime}} \sum_{i=0}^{k}\left(\theta_{i}\right)_{\eta=j \pi}\right]^{2} .
$$

The optimal estimates of $h_{f}$ and $h_{\theta}$ for single-walled (SWCNT) kerosene oil are $h_{f}=-0.338076$, $h_{\theta}=-0.112645$ and those for multi-walled (MWCNT) kerosene oil are $h_{f}=-0.373325, h_{\theta}=-0.122976$. Figures 2 and 3 are drawn to see the relative total residual errors for SWCNT and MWCNT kerosene oil, respectively.

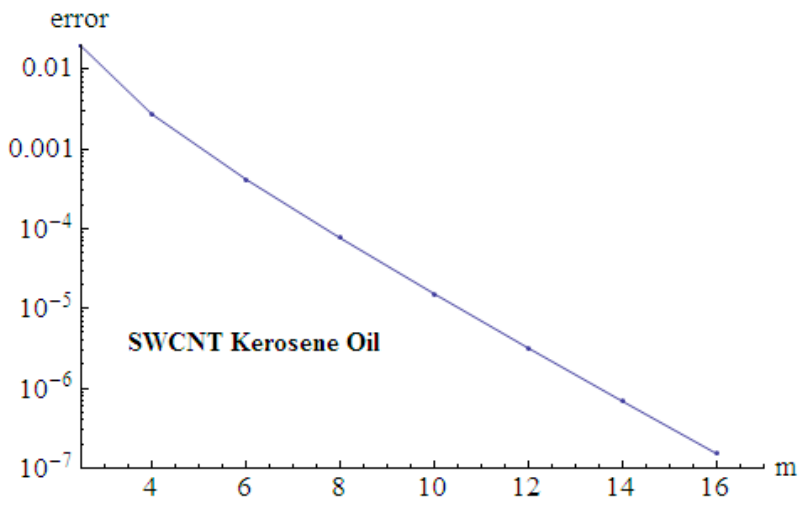

Figure 2. Total error vs. order of approximations.

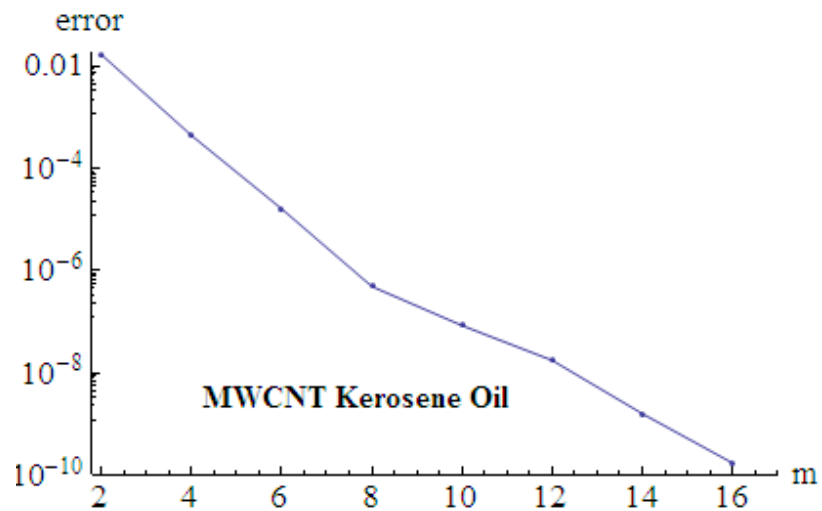

Figure 3. Total error vs. order of approximations. 


\section{Results and Discussion}

The flow and heat transfer of CNTs (SWCNTs and MWCNTs) with kerosene oil as a base liquid are investigated. The governing set of nonlinear differential equations is numerically solved. The impact of $A$ on $f^{\prime}(\eta)$ is plotted in Figure 4 for kerosene oil for SWCNTs and MWCNTs. It is noticed that the velocity field rises for the increment in $A$ for both $A>1$ and $A<1$. On the other side, for $A>1$ and $A<1$, the related thickness of boundary layer has a reverse trend, but for $A=1$, no boundary layer is found. This means that the surface and ambient velocities are the same. The velocity field is dominant for single-walled tubes as compared with multi-walled tubes. Figure 5 illustrates the impact of $\phi$ on $f^{\prime}(\eta)$. It is observed that velocity distribution is the mounting function for the increment in $\phi$ for SWCNTs and MWCNTs. The increment in nanomaterial volume fraction leads to rise in the convective flow. It is likewise noticed that $f^{\prime}(\eta)$ enhances for kerosene oil nanoliquid for MWCNT as compared with SWCNT. The significance of magnetic parameter on the velocity field is outlined in Figure 6 . The velocity $f^{\prime}(\eta)$ and related boundary layer decrease for larger estimates of the magnetic estimator. The increment in $M$ demonstrates the rise in resistive power (Lorentz force) and, therefore, the velocity of the liquid reduces. It is additionally noticed that velocity distribution is dominated for MWCNT as compared with SWCNT kerosene oil. Figure 7 is drawn for the behavior of $m$ on $f^{\prime}(\eta)$. It is analyzed that, for the higher power index, the velocity profile shows reduction for SWCNTs and MWCNTs using base liquid kerosene oil.

An analysis of $E c$ on $\theta(\eta)$ is portrayed in Figure 8. It is worth mentioning that $\theta(\eta)$ becomes higher for the increment in Ec for both SWCNT and MWCNT. The increment in Eckert number leads to larger drag forces between the fluid materials. Consequently, more heat is induced and the temperature distribution increases. The influence of $\phi$ on $\theta(\eta)$ is drawn in Figure 9. Here, temperature distribution reduces with the increase in $\phi$. Additionally, the increment in the nanomaterial volume fraction causes the improvement of the convective heat phenomenon from heated liquid along the cold surface, and consequently, temperature reduces. It is additionally noted that the temperature distribution is dominant for MWCNT as compared with SWCNT. Figure 10 outlines the significance of the temperature in light of an adjustment in the estimations of the radiation parameter $R_{d}$ for MWCNT and SWCNT. Obviously, the temperature distribution and related boundary layer thickness improve for higher values of the radiation estimator $R_{d}$. It is obvious that the surface heat flux increments under the effect of thermal radiation. Consequently, temperature enhances inside the boundary layer region.

Table 1 displays the thermophysical characteristics of the base liquid kerosene oil with carbon nanotubes. Table 2 is set up for the square average residual errors of governing problems at various orders of approximations. It is noticed that the square average residual error diminishes as the request of estimation rises for SWCNTs and MWCNTs using kerosene oil. Table 3 is drawn for the numerical values of the friction estimator for various estimates of different related parameters. It is examined that the friction estimator is larger for higher estimates of $m, M, \phi$, and $\alpha$, while it decreases for larger $A$ for both SWCNTs and MWCNTs. Table 4 is set up for the numerical estimates of local Nusselt number for different values of different appropriate parameters. It is examined that the local Nusselt parameter rises for larger $A, R_{d}$, Ec, and $\phi$, while it lessens for increments in $\alpha$ and $M$ for both single-walled and multi-walled carbon nanotubes. Table 5 exhibits the relative investigation of the skin fraction coefficient with the past work of Pop et al. [45] and Sharma and Singh [46] in limiting cases. It is established that all the outcomes have a decent understanding. 


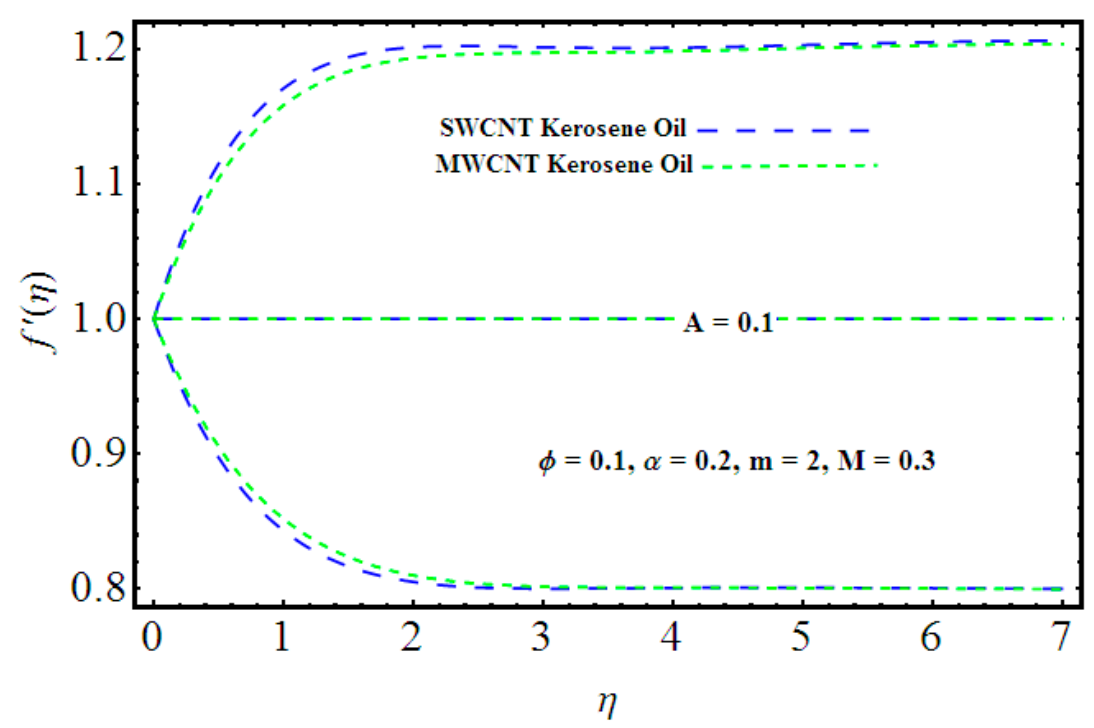

Figure 4. Impact of $A$ on velocity $f^{\prime}(\eta)$.

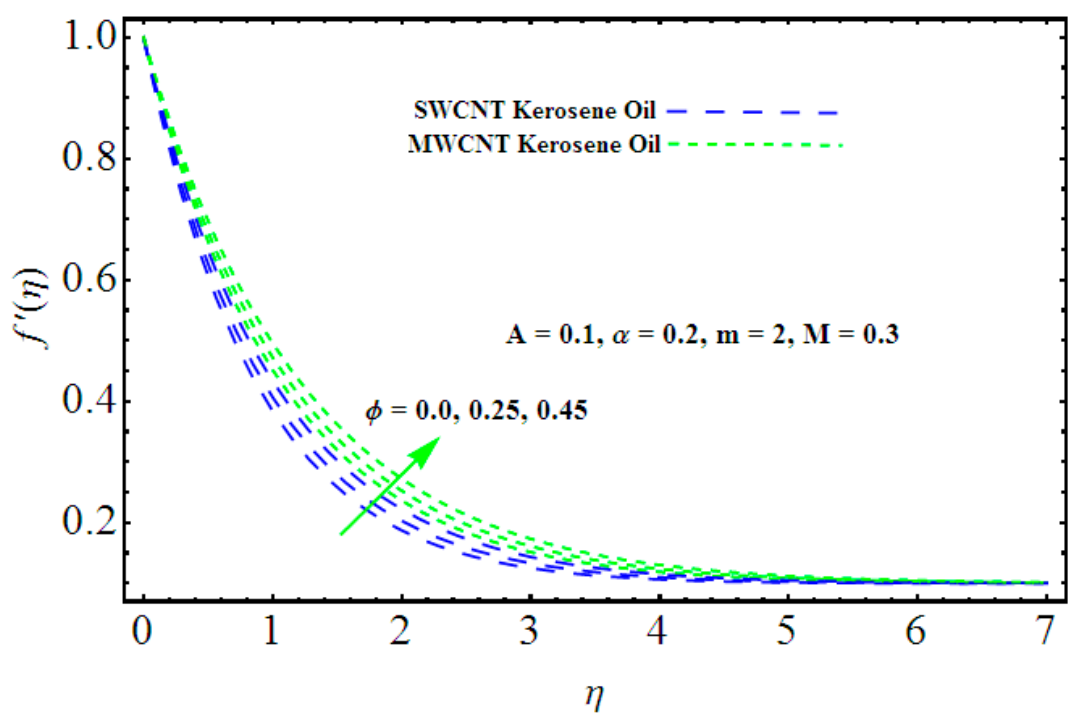

Figure 5. Impact of $\phi$ on velocity $f^{\prime}(\eta)$.

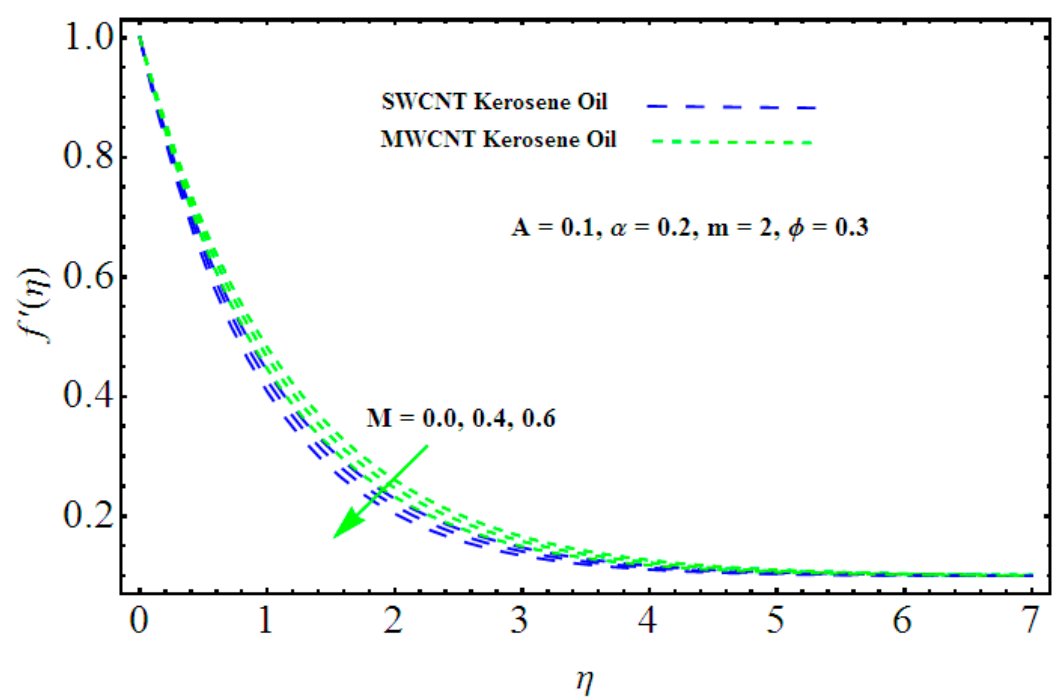

Figure 6. Impact of $M$ on velocity $f^{\prime}(\eta)$. 


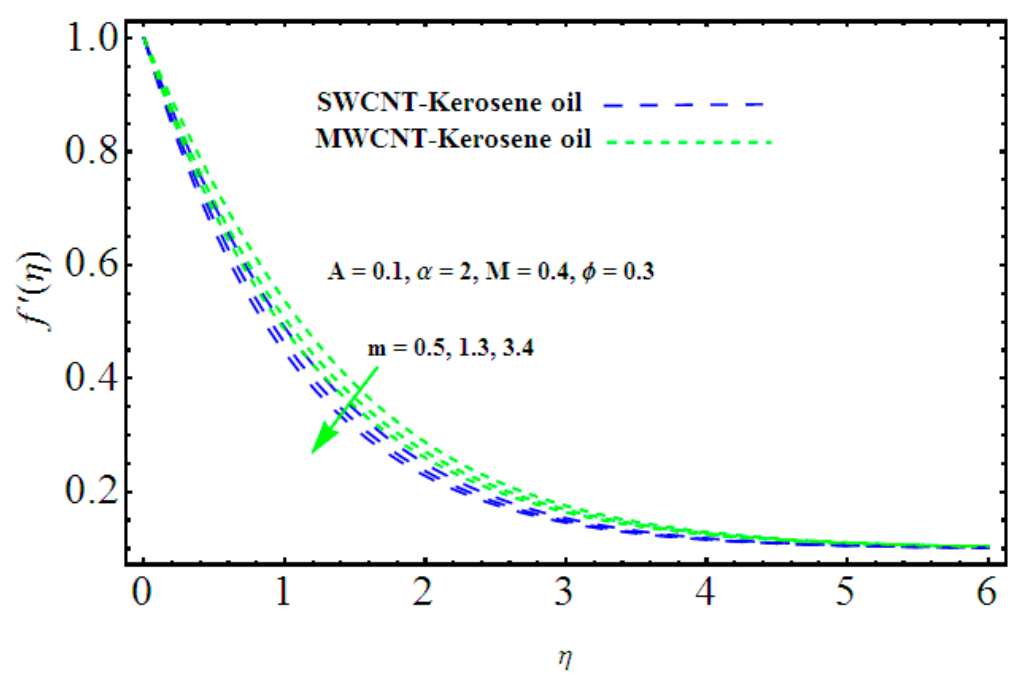

Figure 7. Impact of $m$ on velocity $f^{\prime}(\eta)$.

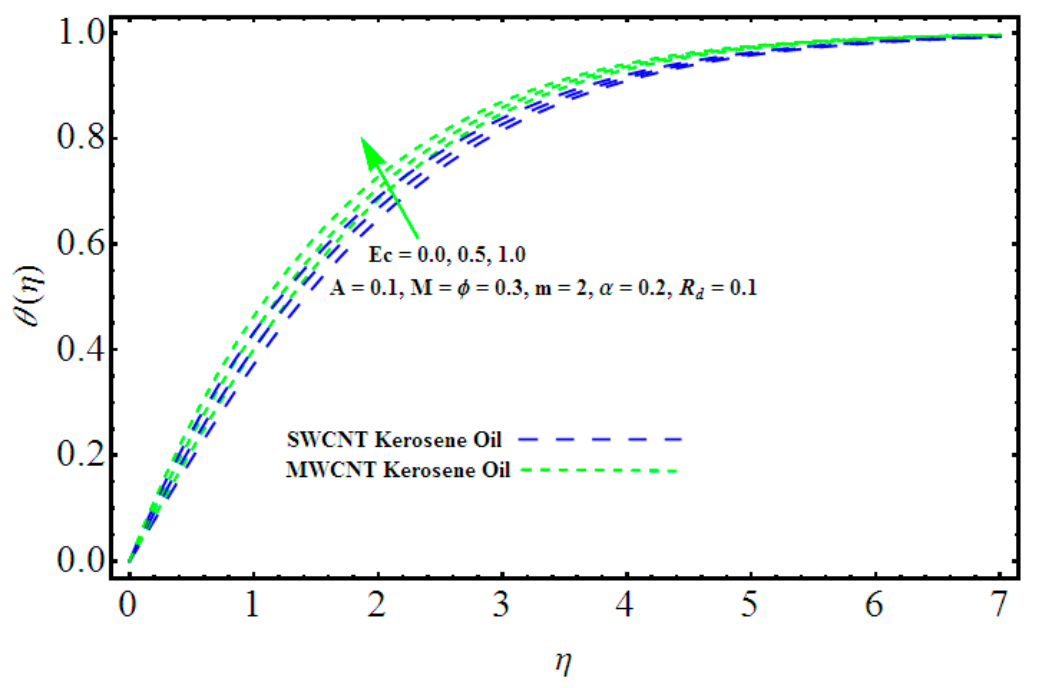

Figure 8. Impact of $E c$ on velocity $\theta(\eta)$.

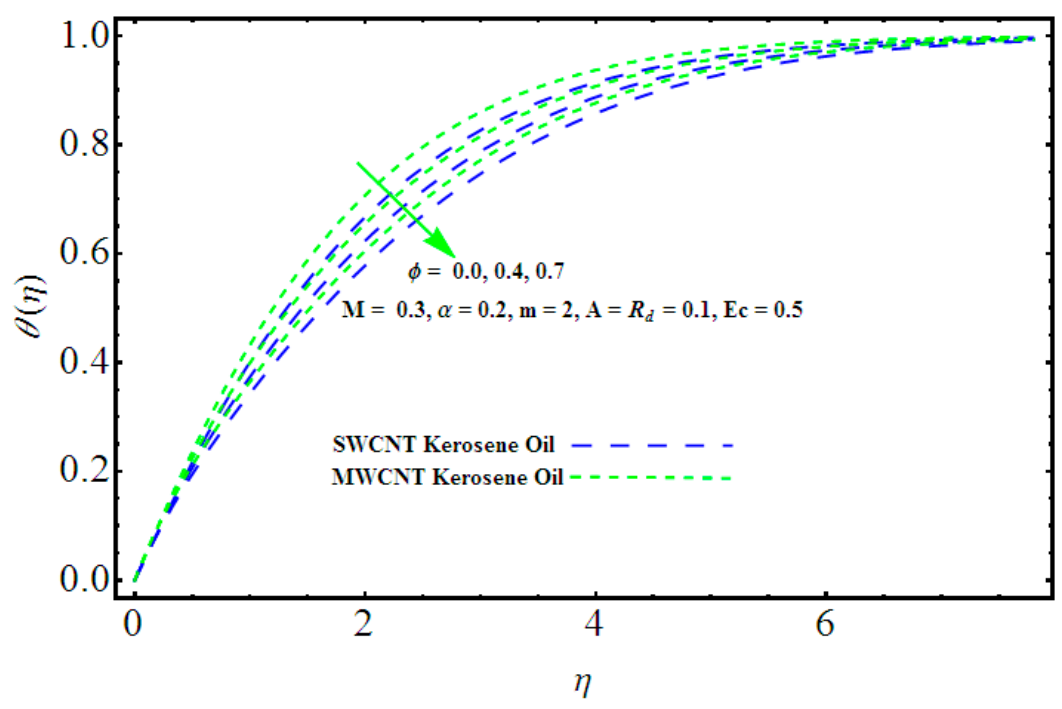

Figure 9. Impact of $\phi$ on velocity $\theta(\eta)$. 


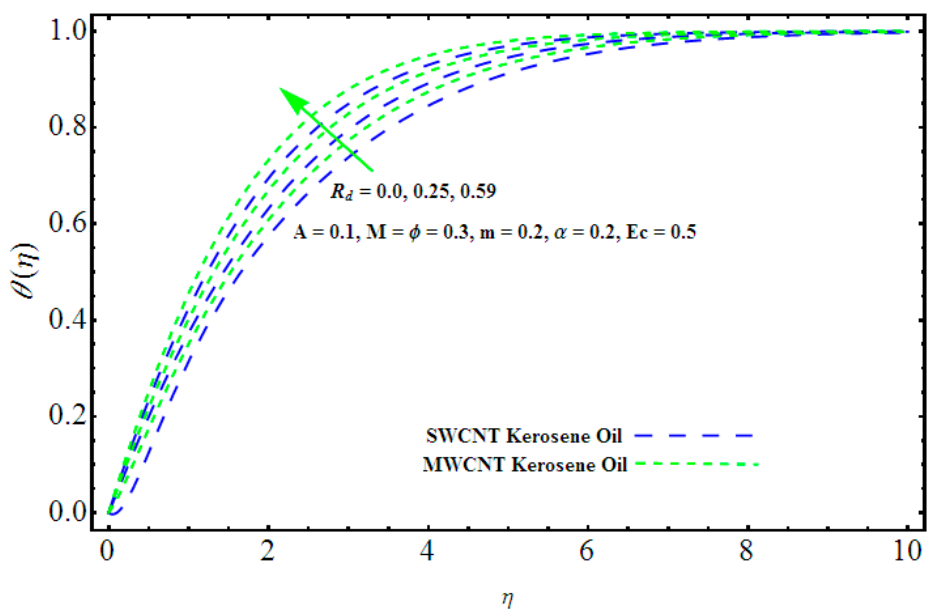

Figure 10. Impact of $E c$ on velocity $\theta(\eta)$.

Table 1. Data of thermophysical properties for the given particles and fluid. MWCNT, multi-walled carbon nanotube; SWCNT, single-walled carbon nanotube.

\begin{tabular}{cccc}
\hline Properties & Base Fluid & \multicolumn{2}{c}{ Particles } \\
\hline & Kerosene Oil & SWCNT & MWCNT \\
\hline$\rho$ & 783 & 2600 & 1600 \\
$c_{p}$ & 2090 & 425 & 796 \\
$k$ & 0.145 & 6600 & 3000 \\
\hline
\end{tabular}

Table 2. Mean square residual errors.

\begin{tabular}{ccccc}
\hline & \multicolumn{2}{c}{ SWCNT } & \multicolumn{2}{c}{ MWCNT } \\
\hline$k$ & $\varepsilon_{k}^{f}$ & $\varepsilon_{k}^{\boldsymbol{\theta}}$ & $\varepsilon_{k}^{f}$ & $\varepsilon_{k}^{\boldsymbol{\theta}}$ \\
\hline 2 & $3.42849 \times 10^{-6}$ & 0.0372506 & $8.92410 \times 10^{-4}$ & 0.0171806 \\
4 & $4.19794 \times 10^{-7}$ & $2.72977 \times 10^{-2}$ & $1.12544 \times 10^{-6}$ & $4.46668 \times 10^{-3}$ \\
8 & $8.05829 \times 10^{-8}$ & $4.16494 \times 10^{-3}$ & $3.82436 \times 10^{-9}$ & $4.90227 \times 10^{-7}$ \\
12 & $8.02125 \times 10^{-10}$ & $3.18276 \times 10^{-6}$ & $1.07810 \times 10^{-10}$ & $1.75135 \times 10^{-8}$ \\
14 & $7.59501 \times 10^{-10}$ & $1.08974 \times 10^{-7}$ & $1.08022 \times 10^{-11}$ & $1.57636 \times 10^{-9}$ \\
16 & $2.32740 \times 10^{-11}$ & $1.51108 \times 10^{-8}$ & $8.61210 \times 10^{-13}$ & $1.70647 \times 10^{-10}$ \\
\hline
\end{tabular}

Table 3. Skin friction (wall drag) data.

\begin{tabular}{ccccccc}
\hline \multirow{2}{*}{$\boldsymbol{\alpha}$} & \multirow{2}{*}{$\boldsymbol{A}$} & $\boldsymbol{\phi}$ & $\boldsymbol{M}$ & $\boldsymbol{m}$ & \multicolumn{2}{c}{$-C_{f} \boldsymbol{R}_{x}^{\frac{1}{2}}$} \\
\cline { 5 - 7 } & & & & & SWCNT & MWCNT \\
\hline 0.0 & 0.1 & 0.3 & 0.3 & 2 & 2.55298 & 2.75297 \\
0.2 & & & & & 2.69267 & 2.69167 \\
0.4 & & & & & 2.63276 & 2.63177 \\
0.2 & 0.0 & 0.3 & 0.3 & 2 & 2.78805 & 2.78805 \\
& 0.1 & & & & 2.69106 & 2.69106 \\
& 0.2 & & & & 2.54457 & 2.54457 \\
0.2 & 0.1 & 0.0 & 0.3 & 2 & 3.65298 & 3.75297 \\
& & 0.2 & & & 3.69267 & 3.69167 \\
& & 0.4 & & & 3.62276 & 3.62377 \\
& 0.1 & 0.3 & 0.0 & 2 & 2.61848 & 2.60848 \\
& & & 0.2 & & 2.65576 & 2.64576 \\
0.2 & 0.1 & 0.3 & 0.3 & 0.0 & 3.51365 & 3.52365 \\
& & & & 0.2 & 3.55576 & 3.53476 \\
& & & & 0.4 & 3.57869 & 3.57469 \\
\hline
\end{tabular}


Table 4. Heat transfer (Nusselt number) data.

\begin{tabular}{|c|c|c|c|c|c|c|c|}
\hline \multirow[t]{2}{*}{$\alpha$} & \multirow[t]{2}{*}{$A$} & \multirow[t]{2}{*}{$\phi$} & \multirow[t]{2}{*}{$M$} & \multirow[t]{2}{*}{$R_{d}$} & \multirow[t]{2}{*}{$E c$} & \multicolumn{2}{|c|}{$-\boldsymbol{R e}_{x}^{-1 / 2} N u_{x}$} \\
\hline & & & & & & SWCNT & MWCNT \\
\hline 0.0 & 0.1 & 0.3 & 0.3 & 0.1 & 0.5 & 5.84027 & 5.94427 \\
\hline 0.2 & & & & & & 5.64158 & 5.65078 \\
\hline 0.4 & & & & & & 5.32405 & 5.36445 \\
\hline \multirow[t]{3}{*}{0.2} & 0.0 & 0.3 & 0.3 & 0.1 & 0.5 & 5.72660 & 5.72560 \\
\hline & 0.1 & & & & & 5.78191 & 5.77091 \\
\hline & 0.2 & & & & & 5.82148 & 5.81148 \\
\hline \multirow[t]{3}{*}{0.2} & 0.1 & 0.0 & 0.3 & 0.1 & 0.5 & 3.45876 & 3.45876 \\
\hline & & 0.2 & & & & 3.55896 & 3.55896 \\
\hline & & 0.4 & & & & 3.78451 & 3.78451 \\
\hline \multirow[t]{3}{*}{0.2} & 0.1 & 0.3 & 0.0 & 0.1 & 0.5 & 5.65429 & 5.65469 \\
\hline & & & 0.2 & & & 5.64380 & 5.64280 \\
\hline & & & 0.4 & & & 5.62461 & 5.61561 \\
\hline \multirow[t]{3}{*}{0.2} & 0.1 & 0.3 & 0.3 & 0.0 & 0.5 & 6.25429 & 6.25129 \\
\hline & & & & 0.2 & & 7.34380 & 7.34281 \\
\hline & & & & 0.4 & & 7.62461 & 7.63461 \\
\hline \multirow[t]{3}{*}{0.2} & 0.1 & 0.3 & 0.3 & 0.1 & 0.0 & 4.15419 & 4.15229 \\
\hline & & & & & 0.2 & 4.34280 & 4.35282 \\
\hline & & & & & 0.4 & 4.62263 & 4.62462 \\
\hline
\end{tabular}

Table 5. Comparison with previous literature.

\begin{tabular}{cccc}
\hline $\boldsymbol{A}$ & Pop et al. [45] & Sharma and Singh [46] & Present Results \\
\hline 0.1 & -0.9694 & -0.969386 & -0.96937 \\
0.2 & -0.9181 & -0.9181069 & -0.91813 \\
0.5 & -0.6673 & -0.667263 & -0.66723 \\
0.7 & & & -0.43345 \\
0.8 & & & -0.29921 \\
0.9 & & & -0.15457 \\
1.0 & & & 0.00000 \\
\hline
\end{tabular}

\section{Conclusions}

The present communication reports a theoretical study on the magnetohydrodynamic flow and the heat exchange of carbon nanotube (CNT)-based nanoliquid over a variable thicker surface. Kerosene oil is taken as the base fluid for the suspension of nanoparticles. Two types of carbon nanotubes (CNTs) are accounted for saturation in base fluid, particularly the single-walled and multi-walled carbon nanotubes, best known as SWCNTs and MWCNTs. The system of nonlinear equations is gained by a reasonable transformation. Analytic solution is obtained by utilizing a notable procedure called the optimal homotopic analysis technique. The key points are given below:

- MWCNTs causes enhancement in velocity field as compared with SWCNTs when there is an increment in the nanoparticle volume fraction $\phi$.

- Higher values given to the magnetic number reduce the flow velocity and are dominant for MWCNTs as compared with SWCNTs.

- $\quad$ Temperature profile rises with an increment in radiation estimator for both SWCNT and MWCNT.

- Augmented values of Eckert number enhance the thermal distribution, but lesser for SWCNT as compared with MWCNT.

- $\quad$ Friction coefficient rises for increments in $m, M, \phi$, and $\alpha$ for both type of nanotubes.

- Heat transfer rate lessens for increments in $\alpha$ and $M$ for both SWCNT and MWCNT. 
Author Contributions: Conceptualization, A.S. and G.R.; methodology, A.S.; software, A.S., G.R., I.K.; validation, A.S., I.K. and G.R.; formal analysis, A.S., I.K. and G.R., E.-S.M.S. and A.H.S.; investigation, A.S. and G.R.; resources, I.K., E.-S.M.S. and A.H.S.; data curation, A.S.; writing-original draft preparation, A.S., I.K. and G.R.; writing-review and editing, A.S., I.K. and G.R., E.-S.M.S. and A.H.S.; visualization, A.S. and G.R.; supervision, A.S.; project administration, A.S.; funding acquisition, I.K., E.-S.M.S. and A.H.S. All authors have read and agreed to the published version of the manuscript.

Funding: This research was funded by Researchers Supporting Project number (RSP-2019/33), King Saud University, Riyadh, Saudi Arabia.

Acknowledgments: Researchers Supporting Project number (RSP-2019/33), King Saud University, Riyadh, Saudi Arabia. The first author is supported by the Talented Young Scientist Program of Ministry of Science and Technology of China (Pakistan-19-007).

Conflicts of Interest: The authors declare no conflict of interests.

\section{Nomenclature}

The following abbreviations have been used in this text:

\begin{tabular}{|c|c|c|}
\hline Name/Title & Description & Unit \\
\hline$x, y$ & Cartesian (horizontal and vertical) coordinates & $\mathrm{m}$ \\
\hline$u, v$ & Velocity (horizontal and vertical) components & $\frac{\mathrm{m}}{\mathrm{s}}$ \\
\hline$v_{n f}$ & Kinematic viscosity of the nanofluid & $\frac{\mathrm{m}^{2}}{\mathrm{~s}}$ \\
\hline$\mu_{n f}$ & Dynamic viscosity of the nanofluid & $\mathrm{Pa} \cdot \mathrm{s}$ \\
\hline$B$ & Magnetic field strength & $(\Omega \mathrm{m})^{-1}$ \\
\hline$\rho_{f l}$ & Density of the base fluid & $\mathrm{Kg} \cdot \mathrm{m}^{-3}$ \\
\hline$\rho_{n f}$ & Density of the nanofluid & \\
\hline$k$ & Thermal conductivity & $\mathrm{W} \cdot \mathrm{m}^{-1} \cdot \mathrm{K}^{-1}$ \\
\hline$\alpha$ & Thermal diffiusivity & $\mathrm{m}^{2} \cdot \mathrm{s}^{-1}$ \\
\hline$T, T_{w}, T_{\infty}$ & Temperature distributions & K \\
\hline$U_{w}$ & Stretching velocity & $\mathrm{m} \cdot \mathrm{s}^{-1}$ \\
\hline$C, C_{w}, C_{\infty}$ & Concentration distributions & \\
\hline$D_{B}$ & Brownian diffusion & \\
\hline$D_{T}$ & Thermophoresis & \\
\hline $\mathrm{Nu}$ & Nusselt number & \\
\hline$S h$ & Sherwood number & \\
\hline$C_{f}$ & Drag force coefficient & \\
\hline$N_{b}$ & Brownian diffusion parameter & \\
\hline$N_{t}$ & Thermophoresis parameter & \\
\hline$b$ & Integer & \\
\hline SWCNTs & Single-walled carbon nanotubes & \\
\hline MWCNTs & Multi-walled carbon nanotubes & \\
\hline CNTs & Carbon nanotubes & \\
\hline MHD & Magnetohydrodynamic & \\
\hline
\end{tabular}

\section{References}

1. Choi, S. Enhancing Thermal Conductivity of Fluids with Nanoparticles; ASME Publications-Fed: San Francisco, CA, USA, 1995; pp. 99-106.

2. Buongiorno, J. Convective transport in nanofluids. J. Heat Transf. 2006, 128, 240-250. [CrossRef]

3. Buongiorno, J.; Venerus, D.C.; Prabhat, N.; McKrell, T.; Townsend, J.; Christianson, R.; Tolmachev, Y.V.; Keblinski, P.; Hu, L.W.; Alvarado, J.L.; et al. A benchmark study on the thermal conductivity of nanofluids. J. Appl. Phys. 2009, 106, 094312. [CrossRef]

4. Rasool, G.; Zhang, T.; Shafiq, A. Second grade nanofluidic flow past a convectively heated vertical Riga plate. Phys. Scr. 2019, 94, 125212. [CrossRef]

5. Rasool, G.; Zhang, T. Characteristics of chemical reaction and convective boundary conditions in Powell-Eyring nanofluid flow along a radiative Riga plate. Heliyon 2019, 5, e01479. [CrossRef] [PubMed]

6. Rasool, G.; Shafiq, A.; Khalique, C.M.; Zhang, T. Magnetohydrodynamic Darcy Forchheimer nanofluid flow over nonlinear stretching sheet. Phys. Scr. 2019, 94, 105221. [CrossRef] 
7. Rasool, G.; Zhang, T.; Shafiq, A.; Durur, H. Influence of chemical reaction on Marangoni convective flow of nanoliquid in the presence of Lorentz forces and thermal radiation: A numerical investigation. J. Adv. Nanotechnol. 2019, 1, 32-49. [CrossRef]

8. Rasool, G.; Zhang, T.; Shafiq, A. Marangoni effect in second grade forced convective flow of water based nanofluid. J. Adv. Nanotechnol. 2019, 1, 50-61. [CrossRef]

9. Lund, L.A.; Omar, Z.; Khan, I.; Dero, S. Multiple solutions of $\mathrm{Cu}-\mathrm{C}_{6} \mathrm{H}_{9} \mathrm{NaO}_{7}$ and $\mathrm{Ag}-\mathrm{C}_{6} \mathrm{H}_{9} \mathrm{NaO}$ nanofluids flow over nonlinear shrinking surface. J. Cent. South Univ. 2019, 26, 1283-1293. [CrossRef]

10. Lund, L.A.; Omar, Z.; Khan, I.; Raza, J.; Bakouri, M.; Tlili, I. Stability Analysis of Darcy-Forchheimer Flow of Casson Type Nanofluid Over an Exponential Sheet: Investigation of Critical Points. Symmetry 2019, 11, 412. [CrossRef]

11. Rasool, G.; Zhang, T.; Chamkha, A.J.; Shafiq, A.; Tlili, I.; Shahzadi, G. Entropy Generation and Consequences of Binary Chemical Reaction on MHD Darcy-Forchheimer Williamson Nanofluid Flow Over Non-Linearly Stretching Surface. Entropy 2020, 22, 18. [CrossRef]

12. Lund, L.A.; Omar, Z.; Khan, I. Steady incompressible magnetohydrodynamics Casson boundary layer flow past a permeable vertical and exponentially shrinking sheet: A stability analysis. Heat Transf. Asian Res. 2019. [CrossRef]

13. Rasool, G.; Zhang, T. Darcy-Forchheimer nanofluidic flow manifested with Cattaneo-Christov theory of heat and mass flux over non-linearly stretching surface. PLOS ONE 2019, 14, e221302. [CrossRef] [PubMed]

14. Shafiq, A.; Khan, I.; Rasool, G.; Seikh, A.H.; Sherif, E.S.M. Significance of Double Stratification in Stagnation Point Flow of Third-Grade Fluid towards a Radiative Stretching Cylinder. Mathematics 2019, 7, 1103. [CrossRef]

15. Shafiq, A.; Zari, I.; Rasool, G.; Tlili, I.; Khan, T.S. On the MHD Casson Axisymmetric Marangoni Forced Convective Flow of Nanofluids. Mathematics 2019, 7, 87. [CrossRef]

16. Rasool, G.; Shafiq, A.; Tlili, I. Marangoni convective nano-fluid flow over an electromagnetic actuator in the presence of first order chemical reaction. Heat Transf. Asian Res. 2019. [CrossRef]

17. Rasool, G.; Shafiq, A.; Durur, H. Darcy-Forchheimer relation in Magnetohydrodynamic Jeffrey nanofluid flow over stretching surface. In Discrete and Continuous Dynamical Systems_Series S; American Institute of Mathematical Sciences: San Jose, CA, USA, 2019.

18. Rasool, G.; Shafiq, A.; Khalique, C.M. Marangoni forced convective Casson type nanofluid flow in the presence of Lorentz force generated by Riga plate. In Discrete and Continuous Dynamical Systems—Series S; American Institute of Mathematical Sciences: San Jose, CA, USA, 2019.

19. Kim, Y.J.; Shin, T.S.; Choi, H.D.; Kwon, J.H.; Chung, Y.C.; Yoon, H.G. Electrical conductivity of chemically modified multiwalled carbon nanotube/epoxy composites. Carbon 2005, 43, 23-30. [CrossRef]

20. Xue, Q. Model for thermal conductivity of carbon nanotube based composites. Phys. B Condens. Matter 2005, 368, 302-307. [CrossRef]

21. Liu, M.S.; Lin, M.C.C.; I-Te, H.; Wang, C.C. Enhancement of thermal conductivity with carbon nanotube for nanofluids. Int. Commun. Heat Mass Transf. 2005, 32, 1202-1210. [CrossRef]

22. Ding, Y.; Alias, H.; Wen, D.; Williams, R.A. Heat transfer of aqueous suspensions of carbon nanotubes (CNT nanofluids). Int. J. Heat Mass Transf. 2006, 49, 240-250. [CrossRef]

23. Ma, X.; Su, F.; Chen, J.; Bai, T.; Han, Z. Enhancement of bubble absorption process using a CNTs-ammonia binary nanofluid. Int. Commun. Heat Mass. Transf. 2009, 36, 657-660. [CrossRef]

24. Choi, J.; Zhang, Y. Properties and Applications of Single-, Double- and Multi-Walled Carbon Nanotubes. In Aldrich Materials Science; Sigma-Aldrich Co. LLC: Steinheim, Germany, 1995.

25. Sumio, I. Helical microtubules of graphitic carbon. Nature 1991, 354, 354-561.

26. Choi, S.U.S.; Zhang, Z.G.; Yu, W.; Lockwood, F.E.; Grulke, E.A. Anomalous thermal conductivity enhancement in nanotube suspensions. Appl. Phys. Lett. 2001, 79, 2252. [CrossRef]

27. Hone, J. Carbon nanotubes: Thermal properties. In Dekker Encyclopedia of Nanoscience and Nanotechnology; CRC Press: New York, NY, USA, 2004; pp. 603-610.

28. Kamali, R.; Binesh, A. Numerical investigation of heat transfer enhancement using carbon nanotube-based non-Newtonian nanofluids. Int. Commun. Heat Mass Transf. 2010, 37, 1153-1157. [CrossRef]

29. Prajapati, V.; Sharma, P.K.; Banik, A. Carbon nanotubes and its applications. Int. J. Pharm. Sci. Res. 2011, 2, 1099-1107. 
30. Kumaresan, V.; Velraj, R.; Das, S.K. Convective heat transfer characteristics of secondary refrigerant based CNT nanofluids in a tubular heat exchanger. Int. J. Refrig. 2012, 35, 2287-2296. [CrossRef]

31. Wang, J.; Zhu, J.; Zhang, X.; Chen, Y. Heat transfer and pressure drop of nanofluids containing carbon nanotubes in laminar flows. Exp. Therm. Fluid Sci. 2013, 44, 716-721. [CrossRef]

32. Khan, W.A.; Khan, Z.H.; Rahi, M. Fluid flow and heat transfer of carbon nanotubes along a flat plate with Navier slip boundary. Appl. Nanosci. 2013. [CrossRef]

33. Noreen, S.A.; Nadeem, S.; Khan, Z.H. Thermal and velocity slip effects on the MHD peristaltic flow with carbon nanotubes in an asymmetric channel: Application of radiation therapy. Appl. Nanosci. 2013. [CrossRef]

34. Noreen, S.A.; Khan, Z.H. Heat transfer study of an individual multiwalled carbon nanotube due to metachronal beating of cilia. Int. Commun. Heat Mass Transf. 2014, 59, 114-119.

35. Ebaid, A.; al Sharif, M. Application of Laplace transform for the exact effect of a magnetic field on heat transfer of carbon-nanotubes suspended nanofluids. Zeitschrift für Naturforschung A 2015, 70, 471-475. [CrossRef]

36. Haq, R.U.; Nadeem, S.; Khan, Z.H.; Noor, N.F.M. Convective heat transfer in MHD slip flow over a stretching surface in the presence of carbon nanotubes. Phys. B Condens. Matter 2015, 457, 40-47. [CrossRef]

37. Kandasamy, R.; Mohamad, R.; Ismoen, M. Impact of chemical reaction on Cu, Al2O3, and SWCNTs-nanofluid flow under slip conditions. Eng. Sci. Technol. Int. J. 2016, 19, 700-709. [CrossRef]

38. Kandasamy, R.; Muhaimin, I.; Mohammad, R. Single walled carbon nanotubes on MHD unsteady flow over a porous wedge with thermal radiation with variable stream conditions. Alex. Eng. J. 2016, 55, 275-285. [CrossRef]

39. Mohammad, R.; Kandasamy, R. Nanoparticle shapes on electric and magnetic force in water, ethylene glycol and engine oil based Cu, Al and SWCNTs. J. Mol. Liq. 2017, 237, 54-64. [CrossRef]

40. Zhang, P.; Hong, W.; Wu, J.F.; Liu, G.Z.; Xiao, J.; Chen, Z.B.; Cheng, H.B. Effects of surface modification on the suspension stability and thermal conductivity of carbon nanotubes nanofluids. Energy Procedia 2015, 69, 699-705. [CrossRef]

41. Aman, S.; Khan, I.; Ismail, Z.; Salleh, M.Z.; Al-Mdall, Q.M. Heat transfer enhancement in free convection flow of CNTs Maxwell nanofluids with four different types of molecular liquid. Sci. Rep. 2017, 7, 2445. [CrossRef]

42. Soleimani, H.; Baig, M.K.; Yahya, N.; Khodapanah, L.K.; Sabet, M.; Demiral, B.M.R.; Burda, M. Impact of carbon nanotubes based nanofluid on oil recovery efficiency using core flooding. Results Phys. 2018, 9, 39-48. [CrossRef]

43. Taheriang, H.; Alvarado, J.L.; Languri, E.M. Enhanced thermophysical properties of multiwalled carbon nanotubes based nanofluids. Part 1: Critical review. Renew. Sustain. Energy Rev. 2018, 82, 4326-4336. [CrossRef]

44. Wang, R.; Xie, L.; Hameed, S.; Wang, C.; Ying, Y. Mechanisms and applications of carbon nanotubes in terahertz devices: A review. Carbon 2018, 132, 42-58. [CrossRef]

45. Pop, S.; Grosan, T.; Pop, I. Radiation effects on the flow near the stagnation point of a stretching sheet. Technol. Mech. 2004, 25, 100-106.

46. Sharma, P.; Singh, G. Effects of variable thermal conductivity and heat source/sink on MHD flow near a stagnation point on a linearly stretching sheet. J. Appl. Fluid Mech. 2009, 2, 13-21.

47. Haq, R.U.; Khan, Z.H.; Khan, W.A. Thermophysical effects of carbon nanotubes on MHD flow over a stretching surface. Phys. E Low-Dimens. Syst. Nanostruct. 2014, 63, 215-222. [CrossRef]

48. Haq, R.U.; Khan, Z.H.; Khan, W.A.; Shah, I.A. Viscous Dissipation Effects in Water Driven Carbon Nanotubes along a Stream Wise and Cross Flow Direction. Int. J. Chem. React. Eng. 2017, 15. [CrossRef]

49. Hussain, S.T.; Haq, R.U.; Khan, Z.H.; Nadeem, S. Water drivenflow of carbon nanotubes in a rotating channel. J. Mol. Liq. 2016, 214, 136-144. [CrossRef]

50. Haq, R.U.; Rashid, I.; Khan, Z.H. Effects of aligned magneticfield and CNTs in two different base fluids over a moving slip surface. J. Mol. Liq. 2017, 243, 682-688. [CrossRef]

51. Haq, R.U.; Kazmi, S.N.; Mekkaoui, T. Thermal management of water based SWCNTs enclosed in a partiallyheated trapezoidal cavity via FEM. Int. J. Heat Mass Transf. 2017, 112, 972-982. [CrossRef]

52. Haq, R.U.; Soomro, F.A.; Hammouch, Z.; Rehman, S.U. Heat exchange within the partially heated C-shape cavity filled with thewater based SWCNTs. Int. J. Heat Mass Transf. 2018, 127, 506-514. [CrossRef] 
53. Karimipour, A.; Bagherzadeh, S.A.; Taghipour, A.; Abdollahi, A.; Safaei, M.R. A novel nonlinear regression model of SVR as a substitute for ANN to predict conductivity of MWCNT-CuO/water hybrid nanofluid based on empirical data. Phys. A Stat. Mech. Appl. 2019, 521, 89-97. [CrossRef]

54. Karimipour, A.; D'Orazio, A.; Goodarzi, M. Develop the lattice Boltzmann method to simulate the slip velocity and temperature domain of buoyancy forces of FMWCNT nanoparticles in water through a micro flow imposed to the specified heat flux. Phys. A Stat. Mech. Appl. 2018, 509, 729-745. [CrossRef]

55. Safaei, M.R.; Togun, H.; Vafai, K.; Kazi, S.N.; Badarudin, A. Investigation of Heat Transfer Enhancement in a Forward-Facing Contracting Channel Using FMWCNT Nanofluids. Numer. Heat Transf. Part A Appl. 2014, 66, 1321-1340. [CrossRef]

56. Jalali, E.; Akbari, O.A.; Sarafraz, M.M.; Abbas, T.; Safaei, M.R. Heat Transfer of Oil/MWCNT Nanofluid Jet Injection Inside a Rectangular Microchannel. Symmetry 2019, 11, 757. [CrossRef]

57. Aghaei, A.; Sheikhzadeh, G.A.; Goodarzi, M.; Hasani, H.; Damirchi, H.; Afrand, M. Effect of horizontal and vertical elliptic baffles inside an enclosure on the mixed convection of a MWCNTs-water nanofluid and its entropy generation. Eur. Phys. J. Plus 2018, 133, 486. [CrossRef]

58. Esfe, M.H.; Emami, R.; Amiri, M.K. Experimental investigation of effective parameters on MWCNT-TiO2/SAE50 hybrid nanofluid viscosity. J. Therm. Anal. Calorim. 2019. [CrossRef]

59. Bagherzadeh, S.A.; D'Orazio, A.; Karimipour, A.; Goodarzi, M.; Bach, Q.V. A novel sensitivity analysis model of EANN for F-MWCNTs- $\mathrm{Fe}_{3} \mathrm{O}_{4} / \mathrm{EG}$ nanofluid thermal conductivity: Outputs predicted analytically instead of numerically to more accuracy and less costs. Phys. A Stat. Mech. Appl. 2019, 521, 406-415. [CrossRef]

60. Ghasemi, A.; Hassani, M.; Goodarzi, M.; Afrand, M.; Manafi, S. Appraising influence of COOH-MWCNTs on thermal conductivity of antifreeze using curve fitting and neural network. Phys. A Stat. Mech. Appl. 2019, 514, 36-45. [CrossRef]

(C) 2020 by the authors. Licensee MDPI, Basel, Switzerland. This article is an open access article distributed under the terms and conditions of the Creative Commons Attribution (CC BY) license (http://creativecommons.org/licenses/by/4.0/). 